\section{BRAZIULAN JOURNAL \\ OF MEDICAL AND BIOLOGICAL RESEARCH}

www.bjournal.com.br
ISSN 1414-431X

Volume 45 (12) 1102-1340 December 2012

\section{BIOMIDICAL SCIENCES}

AND

CLINICAL INVESTIGATION

Braz J Med Biol Res, December 2012, Volume 45(12) 1276-1283

doi: 10.1590/S0100-879X2012007500162

Dynamics of chest wall volume regulation during constant work rate exercise in patients with chronic obstructive pulmonary disease

L.S. Takara, T.M. Cunha, P. Barbosa, M.K. Rodrigues, M.F. Oliveira, L.E. Nery and J.A. Neder

The Brazilian Journal of Medical and Biological Research is partially financed by

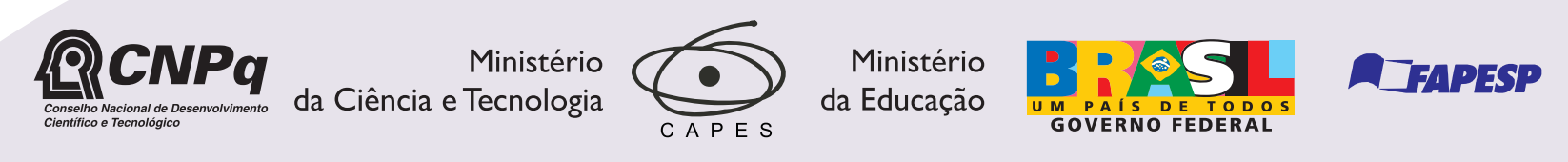

Institutional Sponsors

Sciefo
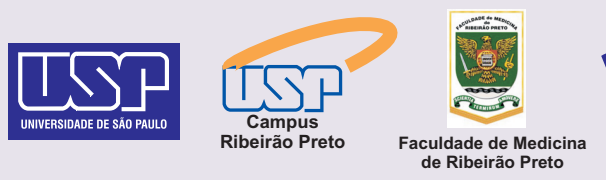

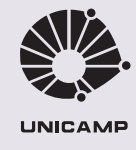

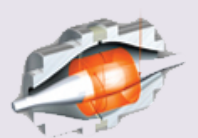

๑ SHIMADZu

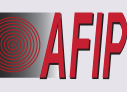

Associaçăa de Incentivo
à Pesquisa

plore High - Performance MS Orbitrap Technology analitica Thermo 


\title{
Dynamics of chest wall volume regulation during constant work rate exercise in patients with chronic obstructive pulmonary disease
}

\author{
L.S. Takara ${ }^{1}$, T.M. Cunha ${ }^{1}$, P. Barbosa1 ${ }^{1}$, M.K. Rodrigues ${ }^{1}$, M.F. Oliveira1, \\ L.E. Nery ${ }^{1}$ and J.A. Neder ${ }^{1,2}$ \\ ${ }^{1}$ Setor de Função Pulmonar e Fisiologia Clínica do Exercício, Disciplina de Pneumologia, \\ Departamento de Medicina, Universidade Federal de São Paulo, São Paulo, SP, Brasil \\ ${ }^{2}$ Division of Respiratory and Critical Care Medicine, Department of Medicine, Queen's University, \\ Kingston, ON, Canada
}

\begin{abstract}
This study evaluated the dynamic behavior of total and compartmental chest wall volumes $\left[\left(V_{C W}\right)=\right.$ rib cage $\left(V_{R C}\right)+a b d o m e n$ $\left(V_{A B}\right)$ ] as measured breath-by-breath by optoelectronic plethysmography during constant-load exercise in patients with stable chronic obstructive pulmonary disease. Thirty males (GOLD stages II-III) underwent a cardiopulmonary exercise test to the limit of tolerance (Tlim) at $75 \%$ of peak work rate on an electronically braked cycle ergometer. Exercise-induced dynamic hyperinflation was considered to be present when end-expiratory $(E E) V_{C W}$ increased in relation to resting values. There was a noticeable heterogeneity in the patterns of $V_{C W}$ regulation as $E E V_{C W}$ increased non-linearly in 17/30 "hyperinflators" and decreased in $13 / 30$ "non-hyperinflators" $(P<0.05)$. $E E V_{A B}$ decreased slightly in 8 of the "hyperinflators", thereby reducing and slowing the rate of increase in end-inspiratory $(E I) V_{C W}(P<0.05)$. In contrast, decreases in $E E V_{C W}$ in the "non-hyperinflators" were due

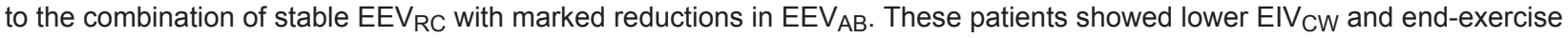
dyspnea scores but longer Tlim than their counterparts $(P<0.05)$. Dyspnea increased and Tlim decreased non-linearly with

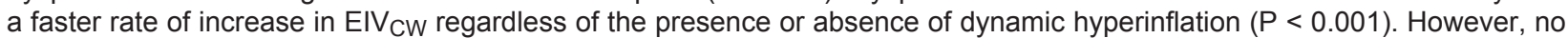
significant between-group differences were observed in metabolic, pulmonary gas exchange and cardiovascular responses to exercise. Chest wall volumes are continuously regulated during exercise in order to postpone (or even avoid) their migration to higher operating volumes in patients with COPD, a dynamic process that is strongly dependent on the behavior of the abdominal compartment.
\end{abstract}

Key words: Exertion; Lung mechanics; COPD; Dyspnea; Exercise test

\section{Introduction}

Dynamic hyperinflation has a key mechanistic role in breathlessness and exercise intolerance in patients with chronic obstructive pulmonary disease (COPD) (1). Several studies have demonstrated the presence of a critical lung volume at which the elastic work of breathing sharply increases exertional dyspnea, thereby reducing exercise capacity (2-4). These data indicate that downward regulation of the chest wall volume $\left(\mathrm{V}_{\mathrm{CW}}\right)$ is of foremost importance to allow longer exercise durations in these patients.

Evidence in this regard, however, has been mostly gathered from discrete measurements of inspiratory capacity (IC) during exercise to estimate end-tidal volumes (2-4).
Although this approach has provided important physiological insights (as reviewed in Ref. 5), it lacks information concerning the individual behaviors of the $V_{C W}$ compartments [i.e., rib cage $\left(V_{R C}\right)$ and abdomen $\left(V_{A B}\right)$ ] (6-11). This is of practical importance since the work of breathing and the respiratory sensations during exercise are strongly influenced by rib cage-abdominal interactions in patients with COPD $(6,7,10)$. In addition, changes in operating lung volumes are estimated from a small number of end-tidal measurements (typically every $2 \mathrm{~min})(2-5)$, thereby precluding a more precise analysis of their time course (kinetics) throughout the exercise bout.

Correspondence: J.A. Neder, Setor de Função Pulmonar e Fisiologia Clínica do Exercício, Disciplina de Pneumologia, Departamento de Medicina, UNIFESP, Rua Prof. Francisco de Castro, 54, 04020-050 São Paulo, SP, Brasil. Fax: +55-11-5571-8384.

E-mail: nederalb@gmail.com

Received May 30, 2012. Accepted August 27, 2012. Available online October 15, 2012. Published December 17, 2012. 
In this context, optoelectronic plethysmography (OEP) has the advantage of carrying out continuous monitoring of the dynamic behavior of total and regional $\mathrm{V}_{\mathrm{CW}}$ during exercise $(8,9)$. This method measures breath-by-breath changes in end-inspiratory (EI) and end-expiratory (EE) $\mathrm{V}_{\mathrm{CW}}, \mathrm{V}_{\mathrm{RC}}$ and $\mathrm{V}_{\mathrm{AB}}$, thereby providing a high-density set of data points, which might be amenable to kinetic analysis. This is likely to provide clinically relevant information, especially during high-intensity, constant work rate exercise test at the limit of tolerance (Tlim), a test format that has been widely used to assess the effects of pharmacological and non-pharmacological interventions in COPD. Assuming, therefore, that any strategy aimed to postpone nearmaximum $V_{\mathrm{CW}}$ (i.e., a critically reduced inspiratory reserve volume) is likely to be advantageous for these patients (2-5), we tested the following hypotheses: i) dyspnea scores would be higher and Tlim lower in patients with faster kinetics and/

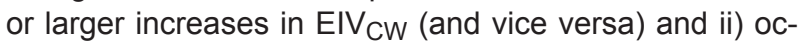
casional reductions in $\operatorname{EEV}_{A B}(6,7,10)$ - conceivably due to the recruitment of expiratory muscles (12-16)-would reduce and slow the increases in $\mathrm{V}_{\mathrm{CW}}$ thereby being beneficial to breathlessness and exercise tolerance in these patients.

The main objective of this study, therefore, was to assess the magnitude and the time course of changes in total and compartmental chest wall volumes by OEP during highintensity, constant work rate exercise to Tlim in patients with moderate-to-severe COPD.

\section{Subjects and Methods}

\section{Subjects}

Thirty males with stable COPD [forced expiratory volume in $1 \mathrm{~s}\left(\mathrm{FEV}_{1}\right) /$ forced vital capacity $<0.7$ and post-bronchodilator $\mathrm{FEV}_{1}<60 \%$ predicted] presenting a long history of smoking (>20 pack-years) and chronic breathlessness (Medical Research Council scores $>2$ ) were enrolled. Main exclusion criteria were: recent exacerbation (within 1 month), long-term oxygen therapy, or arterial oxygen saturation $<85 \%$ at rest, and treatment with oral corticosteroids and anti-histaminics. The study was approved by the Institutional Medical Ethics Committee (Comitê de Ética em Pesquisa do Hospital São Paulo, São Paulo, SP, Brazil) and all subjects gave written informed consent to participate.

\section{Measurements}

Pulmonary function tests. Spirometric tests were performed using a calibrated pneumotachograph (CPF System $^{\mathrm{TM}}$, Medical Graphics Corporation - MGC, USA). Residual volume (in L) and total lung capacity (TLC in L) were measured with a constant-volume body plethysmograph (Elite System ${ }^{\mathrm{TM}}$, MGC). The single breath transfer factor for carbon monoxide ( $\mathrm{DL} \mathrm{CO}$ in $\mathrm{mL} \cdot \mathrm{min}^{-1} \cdot \mathrm{mmHg}^{-1}$ ) was measured using the 1085D System ${ }^{\mathrm{TM}}$ (MGC). Reference values for these tests were those previously obtained for the adult Brazilian population (17-19).
Exercise tests. Cardiopulmonary exercise tests were performed on an electromagnetically braked cycle ergometer (Corival 400, Lode B.V., The Netherlands) with breathby-breath variables being measured with a commercially available metabolic cart ( $\mathrm{CardiO}_{2}$ System $\left.^{\mathrm{TM}}{ }, \mathrm{MGC}\right)$. Subjects initially performed a symptom-limited ramp incremental test (10 W/min) to obtain peak work rate. On a different day, they underwent a Tlim at $70-80 \%$ peak work rate, which was preceded by $1 \mathrm{~min}$ of unloaded pedaling. During these tests, the following data were recorded as mean of $15 \mathrm{~s}$ : oxygen uptake ( $\mathrm{VO}_{2}$ in L/min), carbon dioxide output ( $\mathrm{V}^{\circ} \mathrm{O}_{2}$ in $\mathrm{L} / \mathrm{min}$ ), respiratory exchange ratio, minute ventilation ( $\dot{V}$ $\mathrm{E}$ in $\mathrm{L} / \mathrm{min}$ ), tidal volume (VT in $\mathrm{mL}$ ), breathing frequency, and inspiratory, expiratory and total respiratory time (in s). At baseline, patients were instructed after 3-4 regular tidal breaths to make maximal IC efforts from end-expiratory lung volume to TLC (2-4). Presence and degree of expiratory flow limitation were estimated by determining the fraction of VT in which tidal flow-volume loops met (or exceeded) the boundaries of the maximal flow-volume curve. Expiratory flow limitation was assumed to be present when at least $50 \%$ of the tidal breath satisfied these criteria (5). Oxyhemoglobin saturation was determined by pulse oximetry (in $\%$; Nonin Medical, USA). Subjects were asked to rate their "shortness of breath" and "leg fatigue" at exercise cessation using the 0-10 Borg's category-ratio scale (20).

Chest wall volume measurements. Chest wall kinematics was measured by OEP as previously described (6-10). Briefly, the movement of 89 retro-reflective markers placed front and back over the chest wall from clavicles to pubis was recorded. The markers were positioned on approximately horizontal rows at the following levels: the clavicular line, the manubrio-sternal joint (angle of Louis), the nipples, the xiphoid process, the lower costal margin, the umbilicus, and the anterosuperior iliac crest. Surface landmarks for the vertical columns were: the midlines, both anterior and posterior axillary lines, the midpoint of the interval between the midline and the anterior axillary line, the midpoint of the interval between the midline and the posterior axillary line, and the midaxillary lines. Extra markers were added bilaterally at the midpoint between the xiphoid bone and the most lateral portion of the 10th rib, in the region overlying the lung-apposed ribcage, and in corresponding posterior positions. Each marker was tracked by six video cameras, three in front of the subject and three behind, operating at 60 frames/s and synchronized with co-axial infrared flashing LEDs. Subjects grasped handles positioned laterally to the cycle ergometer in order to lift their arms away from the rib cage so that lateral markers could be visualized. The 3-D coordinates of the markers were calculated with stereo-photogrammetry and linked with a mesh of triangles to create the surface embedding the trunk. The volume of the trunk enclosed by the surface was obtained through a computing algorithm based on the Gauss theorem (OEP System, BTS Bioengineering, Italy) (6-10). 
As in most OEP studies involving patients with COPD $(6,7,10,21)$, the chest wall was first modeled as being composed of two compartments - the rib cage and the abdomen $\left(V_{C W}=V_{R C}+V_{A B}\right.$; see below the description of a post hoc analysis). $V_{R C}$ was assumed to begin at the clavicular level and to terminate at the xiphisternum and lower costal margin. $\mathrm{V}_{\mathrm{AB}}$ was measured down the costal margin to the anterior superior iliac crests. VT measured by OEP was calculated as the difference between end-inspiratory and end-expiratory $V_{C W}\left(E I V_{C W}-E E V_{C W}\right)$. Inspiratory reserve chest wall volume was calculated as the difference between EIV $\mathrm{CW}_{\mathrm{W}}$ and TLC. All values are reported as " $\Delta$ " from resting end-expiratory lung volume (in $\mathrm{L}$ ) and averaged for presentation at selected time points (rest, unload, mid-exercise, and at Tlim).

\section{Data analysis}

Before the kinetic analysis of the OEP data, raw EIV and EEV values of $V_{C W}, V_{R C}$ and $V_{A B}$ were individually reviewed for aberrant data points ( $>20 \%$ of the previous breath), with the remaining values being exponentially smoothed and expressed as 10-s moving averages. Considering that: a) a mono-exponential profile was not found in every test; b) higher-order models did not provide an adequate description of the responses in pilot experiments, and c) to minimize the potential effect of different test durations on the kinetics parameters (e.g., half-time), we obtained an index of the dynamics of chest wall compartments by calculating the fraction of end-exercise-resting volumes reached after an "isotime" of $150 \mathrm{~s}\left(\mathrm{t}_{150}, \%\right)$, i.e., higher $\Delta$ volume at $\mathrm{t}_{150}$ indicated faster volume responses.

In a post hoc analysis, we also investigated whether a paradoxical (inward) movement of the lower ribcage on inspiration would influence our main findings. This was performed by simultaneously comparing the time courses of changes in pulmonary rib cage (from the clavicular level to the xiphisternum), abdominal rib cage (from the xiphisternum to the lower costal margin), $\mathrm{V}_{\mathrm{AB}}$, and $\mathrm{V}_{\mathrm{CW}}$. Briefly, three reproducible consecutive breaths (i.e., between-breath variation in $\mathrm{EIV}_{\mathrm{CW}}$ and $\mathrm{EEV}_{\mathrm{CW}}$ within $10 \%$ ) were randomly chosen near $\mathrm{t}_{150}$ and $\mathrm{Tlim}$ and were used to derive an "average" respiratory cycle. Inspiratory and expiratory phases of the breathing cycles were calculated from the $\mathrm{V}_{\mathrm{CW}}$ signal. As previously suggested by Aliverti et al. (22), we defined the presence of the paradox when the inspiratory paradox time (the fraction of inspiratory time during which the abdominal rib cage volume decreased) at $\mathrm{t}_{150}$ and/or Tlim was larger than $20 \%$.

\section{Statistical analysis}

If not otherwise stated, data are reported as means $\pm S D$ in Tables and means \pm SEM for OEP data in Figures. Twoway analysis of variance (ANOVA) with repeated measures was used to identify significant between-group differences in $\Delta$ volumes at rest and Tlim. One-way ANOVA was performed to examine statistical differences in other variables at Tlim with appropriate Bonferroni's corrections for multiple comparisons.
Spearman's $\rho$ was used for non-parametric correlation and non-linear regression (power function) was used to express the level of association between selected variables. For all analyses, a statistical significance of 0.05 was used.

\section{Results}

\section{Population characteristics}

On average, patients had moderate-to-severe airflow obstruction and reductions in $\mathrm{DL}_{\mathrm{CO}}$ with increased static lung volumes. Twelve patients were classified as GOLD (Global Initiative for Obstructive Lung Disease) stage II (moderate COPD) and the remaining 18 patients as stage III (severe COPD). Responses at peak exercise were typical of COPD patients with such degrees of disease severity (Table 1).

Table 1. Resting and peak exercise characteristics of the sample.

\begin{tabular}{|c|c|}
\hline Variables & $(N=30)$ \\
\hline \multicolumn{2}{|c|}{ Demographic data/antropometry } \\
\hline Age (years) & $66.5 \pm 8.2$ \\
\hline Body mass $(\mathrm{kg})$ & $68.8 \pm 12.0$ \\
\hline Height $(\mathrm{cm})$ & $168.4 \pm 8.1$ \\
\hline BMI $\left(\mathrm{kg} / \mathrm{m}^{2}\right)$ & $24.1 \pm 3.8$ \\
\hline FVC (L) & $2.96 \pm 0.72$ \\
\hline FVC (\% pred) & $75.5 \pm 14.9$ \\
\hline $\mathrm{FEV}_{1}(\mathrm{~L})$ & $1.27 \pm 0.34$ \\
\hline $\mathrm{FEV}_{1}(\%$ pred $)$ & $43.8 \pm 9.5$ \\
\hline $\mathrm{FEV}_{1} / \mathrm{FVC}$ & $0.43 \pm 0.08$ \\
\hline IC (L) & $2.32 \pm 0.53$ \\
\hline IC (\% pred) & $75.1 \pm 15.1$ \\
\hline TLC (\% pred) & $110.5 \pm 12.9$ \\
\hline $\mathrm{RV}(\%$ pred $)$ & $180.2 \pm 23.0$ \\
\hline $\mathrm{DL}_{\mathrm{CO}}(\%$ pred $)$ & $53.3 \pm 18.1$ \\
\hline $\mathrm{P}_{\mathrm{a}} \mathrm{O}_{2}(\mathrm{mmHg})$ & $72.2 \pm 9.2$ \\
\hline $\mathrm{SaO}_{2}(\%)$ & $94.4 \pm 3.6$ \\
\hline $\mathrm{P}_{\mathrm{a}} \mathrm{CO}_{2}(\mathrm{mmHg})$ & $36.2 \pm 4.7$ \\
\hline \multicolumn{2}{|l|}{ Peak exercise } \\
\hline Power (W) & $70 \pm 14$ \\
\hline$\dot{\mathrm{v}} \mathrm{O}_{2}(\mathrm{~mL} / \mathrm{min})$ & $1184 \pm 312$ \\
\hline$\dot{\mathrm{v}} \mathrm{CO}_{2}(\mathrm{~mL} / \mathrm{min})$ & $1205 \pm 355$ \\
\hline V̀E (L/min) & $46.0 \pm 12.8$ \\
\hline V́E/MVV (\%) & $0.84 \pm 0.18$ \\
\hline $\mathrm{HR}(\mathrm{bpm})$ & $131 \pm 20$ \\
\hline
\end{tabular}

Data are reported as means $\pm \mathrm{SD}$. BMI = body mass index; FVC = forced vital capacity; $\mathrm{FEV}_{1}=$ forced expiratory volume in $1 \mathrm{~s}$; IC = inspiratory capacity; TLC = total lung capacity; $\mathrm{RV}=$ residual volume; $\mathrm{DL}_{\mathrm{CO}}=$ lung diffusing capacity for carbon monoxide; $\mathrm{P}_{\mathrm{a}} \mathrm{O}_{2}=$ oxygen partial pressure in arterial blood; $\mathrm{SaO}_{2}=$ oxyhemoglobin saturation; $\mathrm{P}_{\mathrm{a}} \mathrm{CO}_{2}=$ dioxide partial pressure in arterial blood; $\mathrm{vO}_{2}=$ oxygen uptake; $\mathrm{VCO}_{2}=$ carbon dioxide output; $\mathrm{V} E$ = minute ventilation; $\mathrm{MVV}=$ maximal voluntary ventilation; $\mathrm{HR}=$ heart rate. 
Patterns of ventilatory kinematics during exercise

There was a noticeable heterogeneity in the patterns of $V_{C W}$ regulation during exercise as $E E V_{C W}$ increased non-linearly in 17/30 "hyperinflators" and decreased in 13/30 "non-hyperinflators" ( $P$ < 0.05). Amongst the "hyperinflators", EEV $\mathrm{AB}$ decreased slightly, albeit significantly, in 8 patients (group A) but remained stable in the remaining 9 subjects (group $B$ ). $E E V_{R C}$ and $E I V_{R C}$ increases were larger and faster in group A compared to group $B$ (Figure 1 for representative patients and Figure 2 for mean data; Table 2). There were significant inverse relationships between the magnitude and the time course of $E E V_{A B}$ and $E_{R C}$ in group $A(r=-0.72$ and -0.80 , respectively; $P<$ $0.05)$. There was a trend to a larger end-exercise EIV $\mathrm{CW}_{\mathrm{W}}$ in group $A$ but only its rates of change was significantly faster than in group B (Figures 1 and 2, Table 2). Inspiratory paradox was found in a similar number of patients of both groups (Table 2).

In contrast, the "non-hyperinflators" (group $\mathrm{C}, \mathrm{N}=13$ ) showed marked reductions in $E E V_{A B}$. This finding, in association with a mild increase in $E E V_{R C}$, led to a significant reduction of $E E V_{C W}$. In addition, group $C$ showed the smallest and slowest increases in EIV $\mathrm{RC}_{\mathrm{C}}$ and EIV $_{\mathrm{CW}}$ (Figures 1 and 2, Table 2; $\mathrm{P}<0.05$ ). Inspiratory paradox was less frequently found in these patients compared to the other groups (Table 2).

\section{Between-group comparisons of functional variables at rest}

There were no significant between-group differences in resting functional variables or prevalence of GOLD stages (Table 3; $\mathrm{P}>0.05$ ). Of note, however, $7 / 8$ of patients of group $A$ and $7 / 9$ of group $B$ - but only $5 / 13$ of group $C$ - had

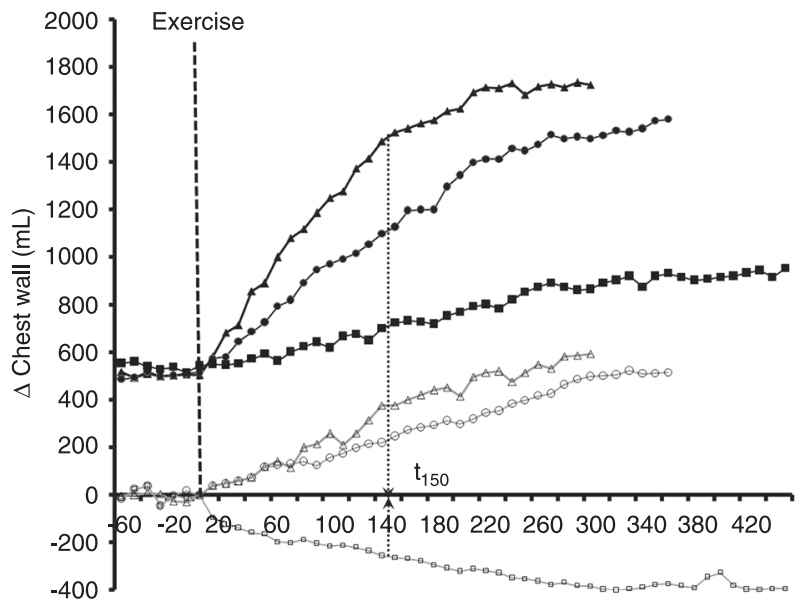

Figure 1. Time course of changes in end-inspiratory (closed symbols) and end-expiratory (open symbols) volumes of the chest wall in patients of groups A (triangles), B (circles) and C (squares). $t_{150}$ is the exercise time elapsed after $150 \mathrm{~s}$. Group $A$ = "hyperinflators" with decreased $E E V_{A B}$; group $B=$ "hyperinflators" with stable $\mathrm{EEV}_{\mathrm{AB}}$; group $\mathrm{C}=$ "non-hyperinflators". resting IC $<80 \%$ predicted, a cut-off value associated with more extensive exploratory flow limitation (EFL) during exercise (23). Resting EFL was also less frequently found in group $\mathrm{C}$ (Table 3 ).

\section{Exercise tolerance and cardiopulmonary responses}

The Tlim of group $\mathrm{C}$ was significantly higher compared to the other groups (Figure 2 and Table 2; $P>0.05$ ). There were no significant between-group differences in metabolic, pulmonary gas exchange and cardiovascular responses to exercise (Table 2; $P>0.05$ ). Dyspnea scores, however, were larger than leg effort ratings at Tlim in group $A$, whereas the opposite was found in group $C$ (Table 2 ; $P<0.05$ ). Interestingly, dyspnea increased and Tlim decreased non-linearly as the kinetics of EIV $\mathrm{CW}_{\mathrm{W}}$ was faster in the whole sample (Figure 3; $\mathrm{P}<0.05$ ).
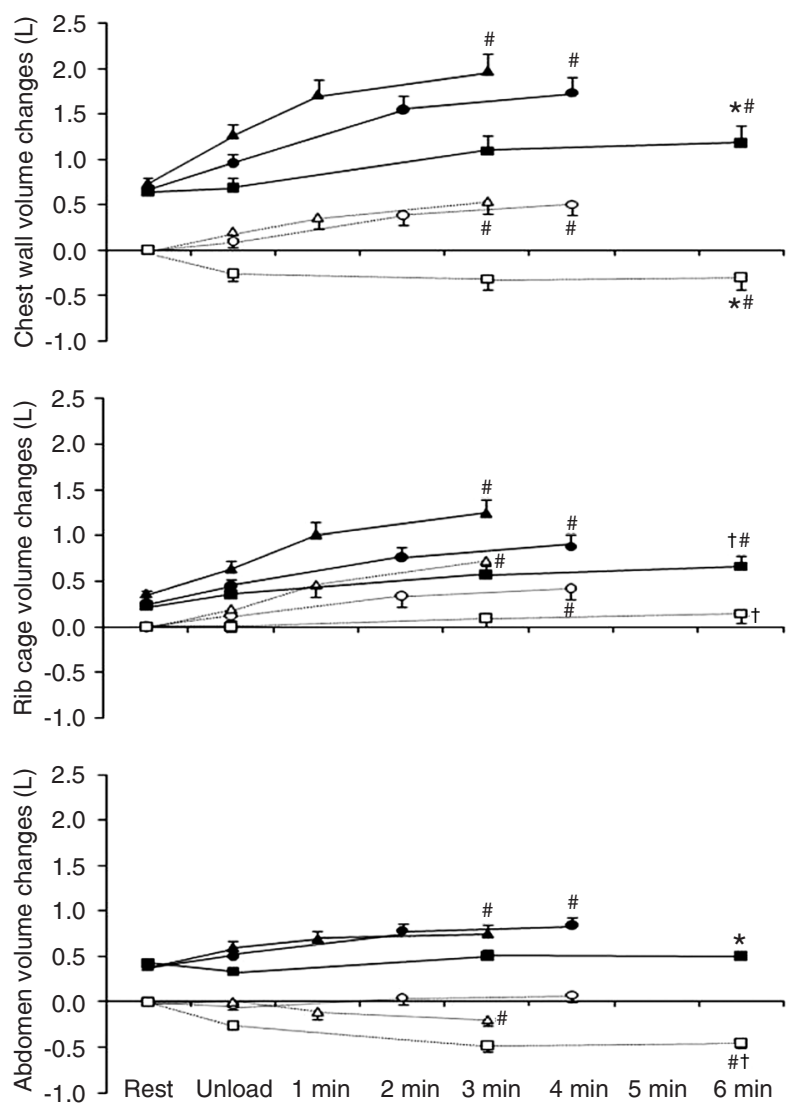

Figure 2. Changes in end-inspiratory (closed symbols) and endexpiratory (open symbols) volumes of the chest wall, rib cage and abdomen as a function of time during constant work rate exercise in patients of groups A (triangles), B (circles) and C (squares). Data are reported as means \pm SEM. Time points represent rest, unload pedaling, mid-exercise, and exercise cessation for each group. $\mathrm{P}<0.05$ ( ${ }^{*}$ group $\mathrm{C}$ vs groups $\mathrm{A}$ and $\mathrm{B}$; † group $\mathrm{A}$ vs group $B$ vs group $C$; \#within-group differences from rest (two-way ANOVA with repeated measures). See Figure 1 for explanation of groups. 
Table 2. Physiological responses to constant work rate exercise in chronic obstructive pulmonary disease patients showing different patterns of changes in compartmental chest wall volumes measured by optoelectronic plethysmography (OEP).

\begin{tabular}{|c|c|c|c|}
\hline Variables & Group A $(N=8)$ & Group B $(N=9)$ & Group C $(N=13)$ \\
\hline Power (W) & $61 \pm 11$ & $63 \pm 21$ & $59 \pm 13$ \\
\hline Tlim (s) & $318 \pm 112^{a}$ & $348 \pm 94^{a}$ & $462 \pm 161^{b}$ \\
\hline \multicolumn{4}{|l|}{ Metabolic } \\
\hline$\dot{\mathrm{v}} \mathrm{O}_{2}(\mathrm{~mL} / \mathrm{min})$ & $1026 \pm 231$ & $1023 \pm 234$ & $1002 \pm 264$ \\
\hline RER & $1.02 \pm 0.09$ & $1.07 \pm 0.10$ & $1.06 \pm 0.07$ \\
\hline \multicolumn{4}{|l|}{ Ventilatory } \\
\hline v̀E (L/min) & $39.1 \pm 9.8$ & $40.2 \pm 10.5$ & $42.3 \pm 14.4$ \\
\hline $\mathrm{VT}(\mathrm{L})$ & $1.22 \pm 0.34$ & $1.26 \pm 0.27$ & $1.42 \pm 0.31$ \\
\hline TI/TTOT & $0.36 \pm 0.03$ & $0.37 \pm 0.03$ & $0.33 \pm 0.03$ \\
\hline VT/TI (L/s) & $1.81 \pm 0.45$ & $1.82 \pm 0.52$ & $2.11 \pm 0.63$ \\
\hline VT/TE (L/s) & $1.02 \pm 0.27$ & $1.07 \pm 0.27$ & $1.18 \pm 0.41$ \\
\hline \multicolumn{4}{|l|}{ Volume changes } \\
\hline \multicolumn{4}{|l|}{ EIV $_{\mathrm{CW}}$} \\
\hline$\Delta(\mathrm{L})$ & $1.24 \pm 0.20 * a$ & $1.06 \pm 0.16^{* a}$ & $0.53 \pm 0.11^{* b}$ \\
\hline $\mathrm{t}_{150}(\% \Delta)$ & $68 \pm 8^{a}$ & $51 \pm 10^{b}$ & $36 \pm 6^{c}$ \\
\hline \multicolumn{4}{|l|}{$\mathrm{EEV}_{\mathrm{CW}}$} \\
\hline$\Delta(\mathrm{L})$ & $0.53 \pm 0.12^{\star a}$ & $0.50 \pm 0.10 * a$ & $-0.29 \pm 0.12^{\star b}$ \\
\hline $\mathrm{t}_{150}(\% \Delta)$ & $76 \pm 6^{a}$ & $57 \pm 8^{b}$ & $74 \pm 10^{a}$ \\
\hline \multicolumn{4}{|l|}{ EIV $_{R C}$} \\
\hline$\Delta(\mathrm{L})$ & $0.87 \pm 0.14^{\star a}$ & $0.62 \pm 0.13^{\star b}$ & $0.45 \pm 0.09 * \mathrm{c}$ \\
\hline $\mathrm{t}_{150}(\% \Delta)$ & $64 \pm 7^{a}$ & $48 \pm 8^{b}$ & $38 \pm 7^{c}$ \\
\hline \multicolumn{4}{|l|}{$\mathrm{EEV}_{\mathrm{RC}}$} \\
\hline$\Delta(\mathrm{L})$ & $0.72 \pm 0.10 * a$ & $0.43 \pm 0.11^{* b}$ & $0.19 \pm 0.10^{c}$ \\
\hline $\mathrm{t}_{150}(\% \Delta)$ & $79 \pm 11^{a}$ & $54 \pm 7^{b}$ & $65 \pm 11^{a}$ \\
\hline \multicolumn{4}{|l|}{ EIV $_{A B}$} \\
\hline$\Delta(\mathrm{L})$ & $0.36 \pm 0.06^{\star a}$ & $0.44 \pm 0.09 * a$ & $0.07 \pm 0.06^{b}$ \\
\hline $\mathrm{t}_{150}(\% \Delta)$ & $77 \pm 9$ & $74 \pm 10$ & - \\
\hline \multicolumn{4}{|l|}{$E E V_{A B}$} \\
\hline$\Delta(\mathrm{L})$ & $-0.29 \pm 0.02^{* a}$ & $0.07 \pm 0.06^{b}$ & $-0.49 \pm 0.06^{* c}$ \\
\hline$t_{150}(\% \Delta)$ & $76 \pm 8$ & - & $73 \pm 9$ \\
\hline $\mathrm{IRV}_{\mathrm{CW}}(\mathrm{L})$ & $0.37 \pm 0.29 a$ & $0.45 \pm 0.30^{a}$ & $1.17 \pm 0.70^{b}$ \\
\hline $\mathrm{P}(+) / \mathrm{P}(-)$ & $4 / 4^{a}$ & $4 / 5^{a}$ & $2 / 11^{b}$ \\
\hline \multicolumn{4}{|l|}{ Cardiovascular } \\
\hline HR (bpm) & $128 \pm 18$ & $130 \pm 15$ & $132 \pm 20$ \\
\hline $\mathrm{O}_{2}$ pulse $\left(\mathrm{mL} \cdot \mathrm{min}^{-1} \cdot\right.$ beat $\left.^{-1}\right)$ & $8.4 \pm 1.9$ & $8.2 \pm 1.5$ & $7.5 \pm 2.2$ \\
\hline \multicolumn{4}{|l|}{ Oxygenation } \\
\hline $\mathrm{SpO}_{2}(\%)$ & $95(9)$ & $92(7)$ & $94(11)$ \\
\hline \multicolumn{4}{|l|}{ Symptoms } \\
\hline Dyspnea scores & $8(3)^{a}$ & $6(3)^{b}$ & $5(4)^{b}$ \\
\hline Leg effort scores & $5(6)^{a}$ & $6(3)^{a}$ & $9(4.5)^{b}$ \\
\hline Dyspnea-Leg effort scores & $3(4)^{a}$ & $0(2)^{b}$ & $-3(1.5)^{c}$ \\
\hline
\end{tabular}

Data are reported as means \pm SD, means \pm SEM (for OEP data) or median (IQR). Group $A=$ "hyperinflators" with decreased $E E V_{A B}$; group $B=$ "hyperinflators" with stable $E E V_{A B}$; group $\mathrm{C}=$ "non-hyperinflators"; Tlim = limit of tolerance; $\mathrm{VO}_{2}=$ oxygen uptake; RER = respiratory exchange ratio, $\dot{V E}=$ minute ventilation; VT = tidal volume; TI, inspiratory time; TTOT = total respiratory time; TE = expiratory time; $\Delta=$ exercise-rest; EIV = endinspiratory volume; $E E V=$ end-expiratory volume; $C W=$ chest wall; $R C=$ rib cage; $A B=$ abdominal; $\mathrm{t}_{150}=$ at $150 \mathrm{~s} ; \mathrm{IRV}=$ inspiratory reserve volume; $\mathrm{P}=$ inspiratory paradox; HR $=$ heart rate; $\mathrm{SpO}_{2}=$ oxyhemoglobin saturation by pulse oximetry. ${ }^{*} \mathrm{P}<0.05$ compared to rest. Significant differences between groups $(P<0.05)$ are indicated by different superscript letters $(a, b, c)$ (one-way ANOVA). 


\section{Discussion}

The present study used OEP to determine the extent and to estimate the time course (kinetics) of $\mathrm{V}_{\mathrm{CW}}\left(\mathrm{V}_{\mathrm{RC}}+\mathrm{V}_{\mathrm{AB}}\right)$ during constant work rate exercise to Tlim in patients with moderate-to-severe COPD. Apparently this seems to be the first report showing that, apart from the well-described inverse relationship between the magnitude of increase in $\mathrm{EIV}_{\mathrm{CW}}$ (i.e., inspiratory reserve volume decrease) (2-4) and exercise tolerance, end-exercise dyspnea worsened and Tlim decreased non-linearly as the kinetics of EIV $\mathrm{CW}_{\mathrm{W}}$ became faster in patients who showed (groups A and B) or not (group C) chest wall hyperinflation (Figure 3 ). Reductions in $E E V_{A B}$ were beneficial for these outcomes since they prevented fast and large increases in $V_{R C}$ from being fully reflected into even-higher $V_{C W}$ in selected "hyperinflators" (group A). In addition, larger decreases in $E E V_{A B}$ were able to deflate the chest wall in the "non-hyperinflators" who showed stable $V_{R C}$, a finding associated with the highest exercise tolerance (group $\mathrm{C}$ ). Collectively, therefore, our findings indicate that $\mathrm{V}_{\mathrm{CW}}$ is continuously regulated during exercise in order to postpone (or even avoid) its migration to higher operating volumes in patients with COPD, a dynamic process that is strongly dependent on the behavior of the abdominal compartment.
Table 3. Resting characteristics of chronic obstructive pulmonary disease (COPD) patients separated by presence or absence of abdominal recruitment and chest wall hyperinflation determined by optoelectronic plethysmography.

\begin{tabular}{|c|c|c|c|}
\hline Variables & Group A $(N=8)$ & Group B (N = 9) & Group C (N = 13) \\
\hline \multicolumn{4}{|l|}{ General characteristics } \\
\hline Age (years) & $68.2 \pm 8.4$ & $68.2 \pm 9.5$ & $64.3 \pm 7.1$ \\
\hline BMI $\left(\mathrm{kg} / \mathrm{m}^{2}\right)$ & $22.4 \pm 4.1$ & $24.0 \pm 4.2$ & $25.2 \pm 3.0$ \\
\hline GOLD stage (II/III) & $5 / 3$ & $3 / 6$ & $4 / 9$ \\
\hline \multicolumn{4}{|l|}{ Spirometric } \\
\hline FVC (\% pred) & $83.5 \pm 17.1$ & $76.6 \pm 13.5$ & $79.8 \pm 12.8$ \\
\hline $\mathrm{FEV}_{1}(\%$ pred $)$ & $47.1 \pm 11.3$ & $45.7 \pm 5.8$ & $40.3 \pm 9.8$ \\
\hline $\mathrm{FEV}_{1} / \mathrm{FVC}(\%)$ & $41.6 \pm 8.4$ & $44.5 \pm 7.6$ & $43.5 \pm 9.4$ \\
\hline SVC $(\%)$ & $88.3 \pm 15.9$ & $83.0 \pm 16.2$ & $76.0 \pm 16.6$ \\
\hline $\mathrm{EFL}(+) / \mathrm{EFL}(-)$ & $6 / 2^{b}$ & $7 / 2^{\mathrm{b}}$ & $4 / 9^{a}$ \\
\hline \multicolumn{4}{|l|}{ Lung volumes } \\
\hline IC (\% pred) & $73.5 \pm 9.7$ & $78.3 \pm 17.0$ & $73.4 \pm 16.7$ \\
\hline TLC $(\%)$ & $111.8 \pm 14.8$ & $112.8 \pm 17.8$ & $107.8 \pm 6.3$ \\
\hline IC/TLC & $0.30 \pm 0.05$ & $0.31 \pm 0.03$ & $0.32 \pm 0.08$ \\
\hline EELV/TLC & $0.69 \pm 0.05$ & $0.68 \pm 0.03$ & $0.67 \pm 0.08$ \\
\hline $\mathrm{RV}(\%$ pred) & $186.8 \pm 32.5$ & $180.3 \pm 30$ & $176.5 \pm 25.7$ \\
\hline RV/TLC & $0.52 \pm 0.04$ & $0.55 \pm 0.04$ & $0.52 \pm 0.07$ \\
\hline \multicolumn{4}{|l|}{ Lung diffusing capacity } \\
\hline $\mathrm{DL}_{\mathrm{CO}}(\%$ pred $)$ & $46.5 \pm 11.3$ & $56.7 \pm 21.9$ & $54.7 \pm 18.8$ \\
\hline
\end{tabular}

Data are reported as means \pm SD. See Table 2 for explanation of groups. BMI = body mass index; GOLD stages II/III = Global Initiative for Chronic Obstructive Lung Disease in moderate/severe COPD; FVC = forced vital capacity; FEV 1 = forced expiratory volume in $1 \mathrm{~s}$; SVC = slow vital capacity; EFL = expiratory flow limitation; IC = inspiratory capacity; TLC = total lung capacity; EELV = endexpiratory lung volume; $\mathrm{RV}=$ residual volume; $\mathrm{DL}_{\mathrm{CO}}=$ lung diffusing capacity for carbon monoxide. Significant differences between groups $(P<0.05)$ are indicated by different superscript letters ( $a, b, c)$ (one-way ANOVA).
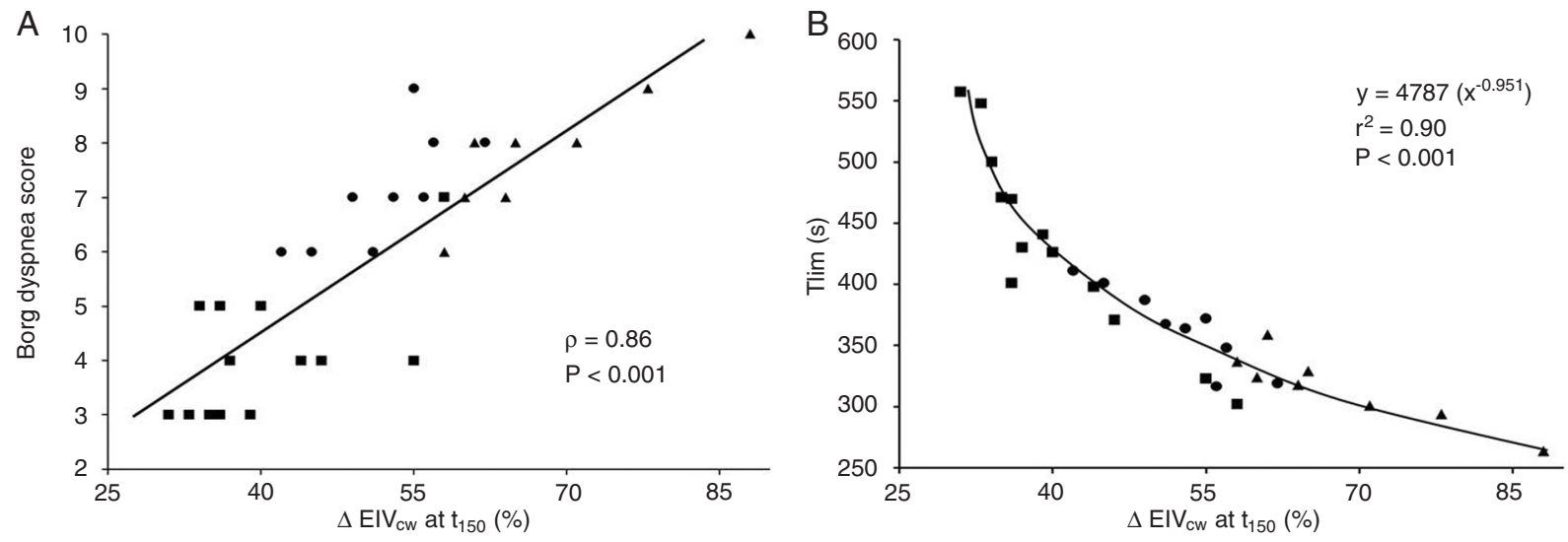

Figure 3. Relationship between end-exercise dyspnea $(A)$ and exercise tolerance limit (Tlim) $(B)$ with an index of the kinetics of endinspiratory volume of the chest wall (EIV $\mathrm{CW}_{\mathrm{W}}$ ) in patients of groups $\mathrm{A}$ (triangles), $\mathrm{B}$ (circles) and $\mathrm{C}$ (squares). $\mathrm{t}_{150}$ is the exercise time elapsed after $150 \mathrm{~s}$. Spearman's $\rho$ was used for non-parametric correlation in Panel $A$ and non-linear regression (power function) in Panel B. See Figure 1 for explanation of groups. 
The prevailing view is that EFL-induced dynamic hyperinflation is a key etiological mechanism of exertional breathlessness in patients with COPD $(5,6)$. The results of the present study agree with this concept as patients in whom resting EFL was greater (groups $A$ and $B$ ) showed larger increases in $\mathrm{V}_{\mathrm{CW}}$, which were related to higher dyspnea scores and lower Tlim. In contrast, those with less EFL (group C) had smaller increases in $V_{C W}$, were less prone to exhibit paradoxical (inward) movement of their lower ribcage on inspiration, reported leg effort as the main exercise-limiting symptom, and showed the highest Tlim (Table 2).

OEP has a number of advantages over the traditional IC-based method to estimate the behavior of the operating lung volumes during exercise $(2,3)$. It not only allows breathby-breath tracking of these volumes but is also not dependent upon patients consistently reaching TLC. Moreover, it is unique as it continuously measures volume changes in the chest wall $\left(\mathrm{V}_{\mathrm{CW}}\right)$ compartments, including those of the abdomen (6-8). Characterization of the dynamics of compartmental $\mathrm{V}_{\mathrm{CW}}$ by OEP in the present study, therefore, provided incremental information to what was known in the field. Therefore, it became apparent that the time course of changes in $\mathrm{V}_{\mathrm{CW}}$ differed markedly among individual patients, being non-linearly related to both dyspnea and exercise tolerance (Figure 3). It is interesting to note that previous studies have found that Tlim decreases hyperbolically as a function of the power output (24) despite similar levels of end-exercise dyspnea and lung hyperinflation in patients with moderate-to-severe COPD (22). In the present study, it could be speculated that Tlim decreased curvilinearly as a result of the selected work rates being placed at different points of the individual power-duration curves (24), with the patients reaching their sensory-mechanical "ceilings" at varying rates (25) (Figure 3). In other words, the rate at which these critical constraints were reached was a function of the absolute exercise intensity and the kinetics of $V_{C W}$. Although this hypothesis needs additional experimental evidence, our data indicate a crucial relevance of the time course at which the mechanical abnormalities develop during constant work rate exercise in patients with COPD.

As also reported in previous OEP studies, we identified two rather opposite patterns of $V_{C W}$ regulation during exercise, i.e., groups A and B ("hyperinflators") vs group C ("nonhyperinflators") $(6,7,10,21)$. However, some of these studies reported that continuous (6) or late exercise (10) decreases in $E E V_{A B}$ were detrimental or not beneficial to maximal incremental exercise capacity in the "non-hyperinflators", respectively. These investigators assumed that the decreases in $E E V_{A B}$ were causally linked to abdominal muscle recruitment, which might have increased the work of breathing and/or reduced the venous return $(26,27)$. Our data suggest that if these deleterious phenomena did occur, they were counterbalanced by the positive effects of lower $E E V_{A B}$ in reducing EIV $_{C W}$ (Figures 1 and 2, Table 2). In addition, the frequency of inspiratory paradox was similar in groups A and B (and lower in group
C), which is not consistent with a dominant role for abdominal recruitment in this deleterious phenomenon. Apart from possible heterogeneities in patients' phenotypes (e.g., degree of emphysema and exercise-induced EFL), this discrepancy might stem from the use of different test paradigms (constant vs incremental exercise), which are associated with dissimilar patterns of ventilatory response. In fact, results of OEP studies with constant work rate exercise tests indicate that exercise tolerance was reduced as abdominal muscle recruitment decreased from GOLD stages I-IV (21); moreover, improved Tlim after pulmonary rehabilitation was associated with larger decrements in $E E V_{A B}(28)$. This issue, however, should be further evaluated by comparing the impact of abdominal muscle recruitment on maximal and submaximal exercise capacity in the same group of COPD patients presenting well-defined "physiological" phenotypes.

The present study has, naturally, some relevant limitations. Lack of gastric and esophageal pressure measurements did not allow measurements of the work of breathing and we acknowledge the descriptive - rather than mechanistic - nature of our investigation. The present authors, like others $(6,7,10,21,28)$, have assumed that changes in $E E V_{A B}$ were linearly related to abdominal muscle recruitment but to date there is no experimental evidence for this assertion. Additional studies are needed to relate the ventilatory kinematic findings to continuous (not only end-exercise) scores of breathlessness. As detailed in the Methods section, we were unable to perform a formal kinetic analysis due to response heterogeneity. However, since there were no differences in baseline volumes and the volumes behaved non-linearly (Figures 1 and 2 ), the chosen strategy ( $\% \Delta$ volume at $\left.t_{150}\right)$ is likely to have adequately described their rate of change. Finally, care should be taken to avoid extrapolation of our results to patients with more severe disease since the bulk of the evidence indicates that substantial decrements in $E E V_{A B}$ are uncommon as disease progresses $(10,29)$.

In conclusion, breath-by-breath analysis of ventilatory kinematics by OEP indicated that the extension and, in particular, the rate of increase in chest wall volumes were important determinants of exercise tolerance in patients with moderate-to-severe COPD. Reductions in abdominal volumes were generally beneficial as they blunted and slowed the increases in chest wall volumes in patients showing severe rib cage hyperinflation and deflated the chest wall in those with stable rib cage volumes. These data indicate the appropriateness of pharmacological and non-pharmacological interventions aimed at lessening the extent and slowing the dynamics of increase of chest wall volumes in this patient population.

\section{Acknowledgments}

Research supported by FAPESP. L.S. Takara was the recipient of a Master fellowship from FAPESP. L.E. Nery and J.A. Neder are level II investigators of CNPq. 


\section{References}

1. Calverley PM. Dynamic hyperinflation: is it worth measuring? Proc Am Thorac Soc 2006; 3: 239-244.

2. O'Donnell DE, Webb KA. Exertional breathlessness in patients with chronic airflow limitation. The role of lung hyperinflation. Am Rev Respir Dis 1993; 148: 1351-1357.

3. O'Donnell DE, Lam M, Webb KA. Measurement of symptoms, lung hyperinflation, and endurance during exercise in chronic obstructive pulmonary disease. Am J Respir Crit Care Med 1998; 158: 1557-1565.

4. O'Donnell DE, Revill SM, Webb KA. Dynamic hyperinflation and exercise intolerance in chronic obstructive pulmonary disease. Am J Respir Crit Care Med 2001; 164: 770-777.

5. Calverley PM, Koulouris NG. Flow limitation and dynamic hyperinflation: key concepts in modern respiratory physiology. Eur Respir J 2005; 25: 186-199.

6. Aliverti A, Stevenson N, Dellaca RL, Lo MA, Pedotti A, Calverley PM. Regional chest wall volumes during exercise in chronic obstructive pulmonary disease. Thorax 2004; 59: 210-216.

7. Aliverti A, Rodger K, Dellaca RL, Stevenson N, Lo MA, Pedotti $A$, et al. Effect of salbutamol on lung function and chest wall volumes at rest and during exercise in COPD. Thorax 2005; 60: 916-924.

8. Cala SJ, Kenyon CM, Ferrigno G, Carnevali P, Aliverti A, Pedotti $A$, et al. Chest wall and lung volume estimation by optical reflectance motion analysis. J Appl Physiol 1996; 81: 2680-2689.

9. Kenyon CM, Cala SJ, Yan S, Aliverti A, Scano G, Duranti $\mathrm{R}$, et al. Rib cage mechanics during quiet breathing and exercise in humans. J Appl Physiol 1997; 83: 1242-1255.

10. Vogiatzis I, Georgiadou O, Golemati S, Aliverti A, Kosmas E, Kastanakis E, et al. Patterns of dynamic hyperinflation during exercise and recovery in patients with severe chronic obstructive pulmonary disease. Thorax 2005; 60: 723-729.

11. Ward ME, Ward JW, Macklem PT. Analysis of human chest wall motion using a two-compartment rib cage model. J Appl Physiol 1992; 72: 1338-1347.

12. Delgado HR, Braun SR, Skatrud JB, Reddan WG, Pegelow DF. Chest wall and abdominal motion during exercise in patients with chronic obstructive pulmonary disease. Am Rev Respir Dis 1982; 126: 200-205.

13. Hopkinson NS, Dayer MJ, Moxham J, Polkey MI. Abdominal muscle fatigue following exercise in chronic obstructive pulmonary disease. Respir Res 2010; 11: 15

14. Kyroussis D, Polkey MI, Hamnegard CH, Mills GH, Green $\mathrm{M}$, Moxham J. Respiratory muscle activity in patients with COPD walking to exhaustion with and without pressure support. Eur Respir J 2000; 15: 649-655

15. Scano G, Gorini M, Duranti R, Misuri G, landelli I, Gigliotti F. Physiological changes during severe airflow obstruction in chronic obstructive pulmonary disease. Monaldi Arch Chest
Dis 1999; 54: 413-416.

16. Vergeret J, Kays C, Choukroun ML, Douvier JJ, Taytard A, Guenard $\mathrm{H}$. Expiratory muscles and exercise limitation in patients with chronic obstructive pulmonary disease. Respiration 1987; 52: 181-188.

17. Pereira CA, Sato T, Rodrigues SC. New reference values for forced spirometry in white adults in Brazil. J Bras Pneumol 2007; 33: 397-406.

18. Neder JA, Andreoni S, Castelo-Filho A, Nery LE. Reference values for lung function tests. I. Static volumes. Braz J Med Biol Res 1999; 32: 703-717.

19. Neder JA, Andreoni S, Peres C, Nery LE. Reference values for lung function tests. III. Carbon monoxide diffusing capacity (transfer factor). Braz J Med Biol Res 1999; 32: 729-737.

20. Borg GA. Psychophysical bases of perceived exertion. Med Sci Sports Exerc 1982; 14: 377-381.

21. Vogiatzis I, Stratakos G, Athanasopoulos D, Georgiadou O, Golemati S, Koutsoukou A, et al. Chest wall volume regulation during exercise in COPD patients with GOLD stages II to IV. Eur Respir J 2008; 32: 42-52.

22. Aliverti A, Quaranta M, Chakrabarti B, Albuquerque AL, Calverley PM. Paradoxical movement of the lower ribcage at rest and during exercise in COPD patients. Eur Respir $J$ 2009; 33: 49-60.

23. Diaz O, Villafranca C, Ghezzo H, Borzone G, Leiva A, MilicEmil J, et al. Role of inspiratory capacity on exercise tolerance in COPD patients with and without tidal expiratory flow limitation at rest. Eur Respir J 2000; 16: 269-275.

24. Neder JA, Jones PW, Nery LE, Whipp BJ. Determinants of the exercise endurance capacity in patients with chronic obstructive pulmonary disease. The power-duration relationship. Am J Respir Crit Care Med 2000; 162: 497-504.

25. Puente-Maestu L, Sanz ML, Sanz P, Ruiz de Ona JM, Rodriguez-Hermosa JL, Whipp BJ. Effects of two types of training on pulmonary and cardiac responses to moderate exercise in patients with COPD. Eur Respir J 2000; 15: 1026-1032.

26. Aliverti A, Macklem PT. How and why exercise is impaired in COPD. Respiration 2001; 68: 229-239.

27. Aliverti A. Lung and chest wall mechanics during exercise: effects of expiratory flow limitation. Respir Physiol Neurobiol 2008; 163: 90-99.

28. Georgiadou O, Vogiatzis I, Stratakos G, Koutsoukou A, Golemati S, Aliverti A, et al. Effects of rehabilitation on chest wall volume regulation during exercise in COPD patients. Eur Respir J 2007; 29: 284-291.

29. Wilkens H, Weingard B, Lo MA, Schena E, Pedotti A, Sybrecht GW, et al. Breathing pattern and chest wall volumes during exercise in patients with cystic fibrosis, pulmonary fibrosis and COPD before and after lung transplantation. Thorax 2010; 65: 808-814. 